\title{
Design of an FRP Cable-stayed Pedestrian Bridge. Morphology, Technology and Required Performances
}

\author{
Attilio Quadrino ${ }^{10000-0002-2100-2000]}$, Marco Damiani ${ }^{\text {[0000-0001-7146-787X] }}$, Rosa Penna ${ }^{2[0000-}$ \\ 0003-3905-5263], Luciano Feo ${ }^{\text {[0000-0002-3180-7478], Nicola Nisticò }}{ }^{\text {[0000-0002-9367-8528] }}$ \\ ${ }^{1}$ Sapienza University of Rome, Department of Structural and Geotechnical Engineering \\ ${ }^{2}$ University of Salerno, Department of Civil Engineering \\ nicola.nistico@uniroma1.it
}

\begin{abstract}
In the past, a pilot project started at the Salerno University to conceive a pedestrian FRP bridge in the campus placed in Fisciano. The project gave the opportunity to start a cooperation among the authors and the result is the preliminary design of a cable stayed bridge, that will be presented after a description of worldwide FRP bridge realizations, including two pioneering cable stayed bridges: the Aberfeldy and the Kolding. The proposed six-span bridge has a total length of $185 \mathrm{~m}$ : a) antennas and decks are assembled through PGFRP elements; b) the PCFRP cables are anchored through a mechanical system optimized by defining the barrel and wedge angles. The solution is presented and discussed with regard of pedestrian comfort, joints and cable system. Specifying that dynamic effects due to wind action are under study, it can be concluded that the Capacity/Demand safety factor resulted greater than one as far as damage and ultimate limit states are concerned.
\end{abstract}

Keywords: GFRP, Cable Stayed Bridges, Connections, Structural Design.

\section{$1 \quad$ Introduction}

Fiber materials Reinforced with Polymeric matrix (FRP) are widely applied worldwide as efficient materials for retrofitting of existing structures. It is well known that they combine lightness and strength, having also good characteristics in terms of stiffness, especially in the case of carbon fibers. The success they had in the renewal of existing structures pushed their application toward the replacement of parts of existing structures and the realization of new ones [1-3].

Bridges, to be mentioned among new constructions, include examples completely made of FRP elements, except for some parts such as the junctions: the material lightness allows to assembly the whole structures in short time, without interrupting the road serviceability. Advantages (e.g. efficiency and sustainability) in terms of cost have been discussed in [4]. Part of costs depends on the material used and the production processes, among which pultrusion, hand lay-up and filament winding can be mentioned. Improvement of hand lay-up process can be pursued through Resin Transfer Molding (RTM) and Vacuum Assisted Resin Transfer Molding (VARTM). The advanced research in the topic of FRP material and structures, combined with some 
important pioneering realizations, stimulated the implementation of 1) manuals and books [5,6]; 2) design codes that include European [7] and Italian [8] proposals.

The feasibility of FRP footbridges is also related to their dynamical behavior when subjected to pedestrian actions: despite their high critical damping (2.5 greater than the value of steel, concrete and steel-concrete composite footbridges), vertical accelerations are, on average, about 3.5 times higher than those of conventional footbridges [9].

The consolidated scientific and technical scenario gave rise to the design of a composite pedestrian Cable Stayed Bridge to be realized in Fisciano (Italy), inside the campus of the University of Salerno. The design process and adopted verification criteria will be discussed here, including some critical aspects consequent to the vibration induced by pedestrian actions.

\section{Worldwide FRP Bridge Realizations: typologies and dynamic characteristics}

Applications of plastic for structural members date back to 1954: Massachusetts Institute of Technology and Monsanto Chemical Company worked together for the House of Future [10]. Implementations of reinforced plastic to bridges date back to the early '70s, when McCormick [11] stimulated their application also proposing, with other colleagues, an optimized reinforced plastic bridge girder presented in [12], where the authors mentioned, among first applications, a reinforced-plastic pedestrian bridge, erected (1972) in Tel-Aviv (Israel). One of the most update discussion on FRP bridges is reported in [3].

Regarding vehicular bridges, adopted solutions combine FRP beams with reinforced concrete decks. Hand lay-up or resin infusion are preferred to pultrusion process. Examples of realizations (Fig. 1) are the bridges placed along the Madrid (Spain) freeway $[13,14]$ : 1 ) open reverse " $\Omega$ " cross sections are transversally connected through reinforced concrete cast in place elements built on glass fiber formworks; 2) the adopted hand lay-up process allowed the tailoring of the girder: a) the bottom flanges are made by hybrid glass-carbon prevalently oriented along the girder axis: b) the webs consist of sandwich panels with polyurethane core and external glass fibers prevalently having $\pm 45^{\circ}$ angles with respect of the girder longitudinal axis. A solved disadvantage was the curing phase process disturbed by the relevant thickness of the in-house made pre-peg laminate: the usually adopted epoxy was substituted developing a low exothermic resin.

Hand lay-up process can be combined with Vacuum Assisted Resin Transfer Molding (VARTM) adopted within a pilot research [15] for the realization of a composite road bridge in Rzeszow (Poland): 1) the GFRP girder consists of: a) U-shaped cross sections having unidirectional and biaxial fabrics combined, as far as webs are concerned, with PVC foam layers in order to form a sandwich panel; b) the "U" beam is internally stiffened through sandwich GFRP/Foam diaphragms; 2) the deck bonded to the girder consists of two GFRP laminated and a PUR foam core, forming a sandwich panel stiffened by vertical GFRP ribs. Regarding all-FRP pedestrian bridges, 
discussed in the following, more relevant applications concern truss, arch, suspension and cable stayed typologies.
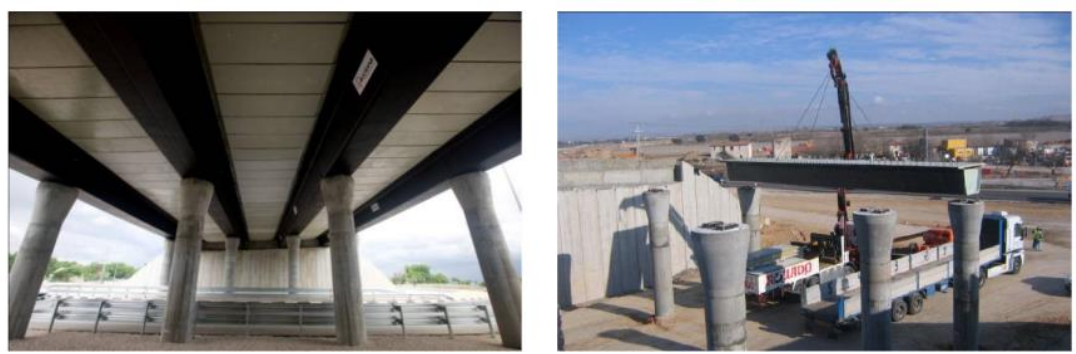

Fig. 1. Vehicular FRP bridges: M111 Madrid (Spain) freeway [13].

\subsection{Truss Typologies}

Pontresina and Prato (Fig. 2) can be mentioned among truss bridges. They are simply supported and consist of PGFRP elements.
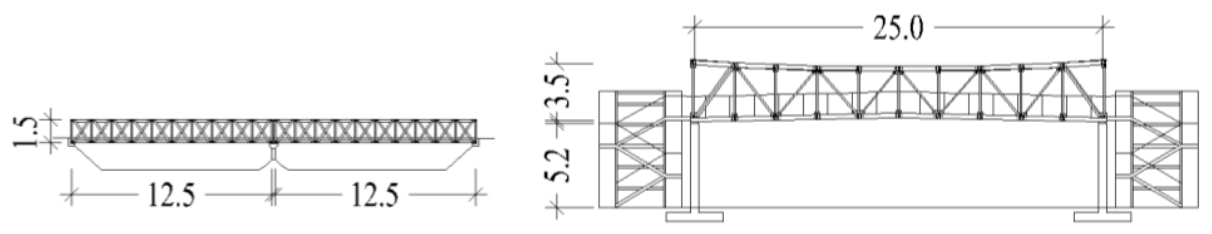

Fig. 2. Truss bridges: Pontresina (left), Switzerland (1997); Prato (right), Italy (2008).

The Pontresina Pedestrian Bridge [16], located at an altitude of $1970 \mathrm{~m}$, is a temporary construction: it is in service from autumn to spring, when it is removed (by helicopter) due to high water. It is assembled through PGFRP elements 1) bolted in one span and 2) adhesively bonded in the other: the joints were further secured with bolts that, not being working at service conditions, supported the adhesion phase (curing included). The adopted pultruded elements mainly consist in a combination of 1) isophthalic polyester resin (50\% in volume), 2) a central placed roving (35\%), 3) combined mats $(15 \%)$, including chopped strand and woven, outside and 4) external protective polyester surface. The global weight of each $(1.93 \times 12.5 \mathrm{~m})$ span is $16.5 \mathrm{kN}$ $\left(0.68 \mathrm{kN} / \mathrm{m}^{2}\right)$, among which $1.5 \mathrm{kN}$ is due to steel supports and bolts. In the summer of 2005, the bridge was moved to be assessed at the Swiss Federal Institute of Technology Lausanne (EPFL): 1) local non-critical damages and defects were removed; 2) the colour of exposed surfaces had a slight change, denoting inessential UV effects; 3 ) the tensile tests carried out on cutout specimens revealed a strength decrease in between 13 and $18 \%$.

Dynamic tests were performed in 1997 and in 2005 [17]. Frequencies and critical damping $(\xi)$ were evaluated for bonded and bolted span resulting 1) quite similar for 
both spans as far as vertical frequencies $(\mathrm{Hz})$ are concerned: $\approx 13(\xi=6.0 \%), 27(\xi=$ $2.0 \%), 38(\xi=6.0 \%)$; 2) higher for bonded span in case of horizontal vibrations. Regarding the first mode it was: a) bonded $\approx 5(\xi=3.0 \%)$ and b) bolted $4(\xi=4.0 \%)$.

The Prato bridge [18] has been conceived for pedestrian and cyclists. It is assembled through PGFRP elements: the deck, supported through R.C. piers, has a width of 1) $3.6 \mathrm{~m}$ at the ends and 2) $2.5 \mathrm{~m}$ in the central part, for a total length of $15 \mathrm{~m}$. The total bridge weight is $\approx 80.00 \mathrm{kN}\left(1.2 \mathrm{kN} / \mathrm{m}^{2}\right)$. The main results of ambient vibration testing are reported in [19] in terms of frequencies (Hz) and critical damping: 1) vertical modes have frequencies equal to $7.5(\xi=2.6 \%)$ and $8.1(\xi=1.7 \%) ; 2)$ lateral modes have frequencies equal to $5.8(\xi=1.8 \%)$ and $9.60(\xi=0.6 \%) ; 3)$ torsional modes have frequencies equal to $2.10(\xi=1.6 \%), 2.7(\xi=1.3 \%), 4.8(\xi=1.4 \%)$ and $9.3(\xi=1.2 \%)$.

\subsection{Arch and Suspension Bridges}

Lleida (Fig. 3) arch and deck $(37.8 \times 3 \mathrm{~m})$ are assembled through PGFRP elements [20]: 1) at least $50 \%$ of reinforcement is combined with a isophthalic polyester resin; 2) the reinforcement consists of fibers, woven and complex mats; 3) the arch box profiles consist of U-shaped profiles, joined with glued flat plates; 4) all joints are bolted and some of them were filled either with a mortar of sand and resin or PVC blocks; 5) the total weight is $\approx 190 \mathrm{kN}\left(1.67 \mathrm{kN} / \mathrm{m}^{2}\right)$. The tests carried out showed that 1) the main frequency is $2.75 \mathrm{~Hz}(\xi=2.5 \% \div \xi=3.0 \%) ; 2)$ the deflection due to a load equivalent to $2 \mathrm{kN} / \mathrm{m}^{2}$ increased, almost linearly, up to $22 \mathrm{~mm}$, with a residual displacement $(7 \mathrm{~mm})$, probably due to the assessment of connections. Further on, numerical simulations [21] allowed to predict vertical accelerations induced by pedestrians, resulting that: 1) the peak values range between 0.52 and $0.68 \mathrm{~m} / \mathrm{s}^{2}$ for damping values in between 1.0 and $2.5 \%$ and consequently 2) a "mean" comfort level can be attributed to the bridge, based on the Sétra classification [22] (see Tab. 3).

The Wilcott bridge (Fig. 3) consists [23,24] of a PGFRP deck $(51.3 \times 2.16 \mathrm{~m})$, whose central part has been ballasted in order to decoupling vertical and torsional modes. The deck is suspended on 20 steel hangers and 2 cables passing on 4 steel hollow backstays. Different authors evaluated modal parameters. According to those reported in [23]: 1) vertical frequencies $(\mathrm{Hz})$ are $0.96(\xi=2.49 \%), 1.51(\xi=1.91 \%)$, $2.21(\xi=0.96 \%), 2.71(\xi=1.89 \%), 3.86(\xi=1.41 \%) ; 2)$ lateral frequencies are 1.08 $(\xi=0.31 \%), 1.56(\xi=1.67 \%), 4.11(\xi=1.34 \%) ; 3)$ the torsional frequency is $3.22(\xi$ $=0.82 \%)$.
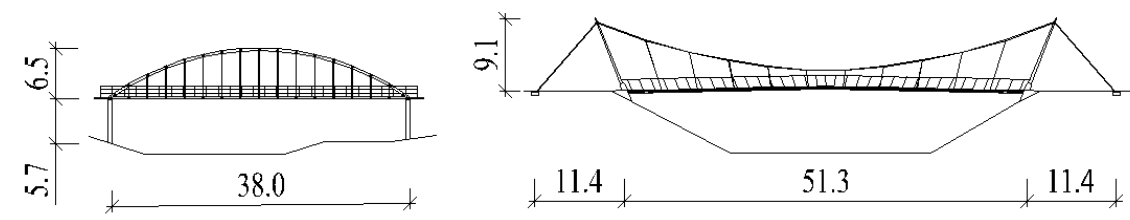

Fig. 3. Left: Lleida, Spain (2001); Right: Wilcott, United Kingdom (2003). 


\subsection{Cable Stayed Bridges}

Aberfeldy and Kolding are pioneering realizations. Deck and antennas of both are realized in GFRP. The adopted cables are respectively made of 1) aramid fiber with a spike system anchorage [25] and 2) PGFRP elements connected through a bolt system [26].

As far as Aberfeldy is concerned (Fig. 4), deck (2.12 m width) and antennas (18.0 $\mathrm{m}$ tall) have been assembled [27] through PGFRP units $(\approx 80 \times 80 \mathrm{~mm})$, first interlocked with "toggle" connections and then adhesively bonded. The 40 ropes are made of a set of dry unbonded filaments (Kevlar 49, type G) contained in a polymeric (low stiff) tube. The bridge includes $184.7 \mathrm{kN}$ of composites $\left(0.80 \mathrm{kN} / \mathrm{m}^{2}\right)$, comprising: 1$)$ deck $(82.2 \mathrm{kN})$ and antennas $(80 \mathrm{kN}) ; 2)$ GFRP parapets $(20 \mathrm{kN})$ and 3) ropes $(2.5$ $\mathrm{kN}$ ). A long-term monitoring program was scheduled, evaluating principal frequencies and critical damping (Tab. 1): data acquired in 1995 and 2000 [27], as well as those acquired in 2011 [28], denote a generalized frequency decay.

Kolding bridge [26], assembled through PGFRP profiles, has (Fig. 5): 1) a deck (3.2-meter width), that includes two I-shaped profiles (1.4 m high); 2) one A-shaped truss tower, comprising vertical "C" profiles and L-shaped bracing elements; 3) 8 PGFRP cables having square cross section; 4) a total weight of $120 \mathrm{kN}\left(\approx 0.8 \mathrm{kN} / \mathrm{m}^{2}\right)$. It is worth noticing that the bridge has been erected in 18 hours, distributed over three nights. The carried out modal identification allowed to measure 1) the first five natural frequencies $(4.30,6.59,11.13,17.09$ and $20.23 \mathrm{~Hz})$ and the corresponding critical percentage damping $(2.87,1.63,2.59,2.09,2.57)$.

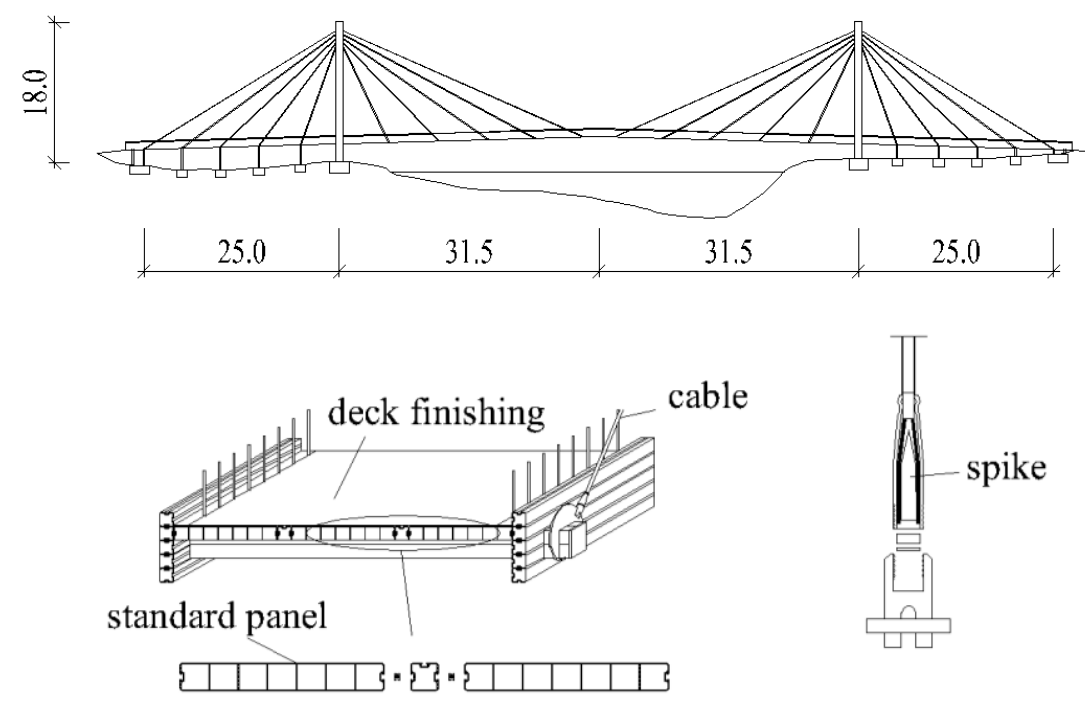

Fig. 4. Aberfeldy, Scotland (1992). 

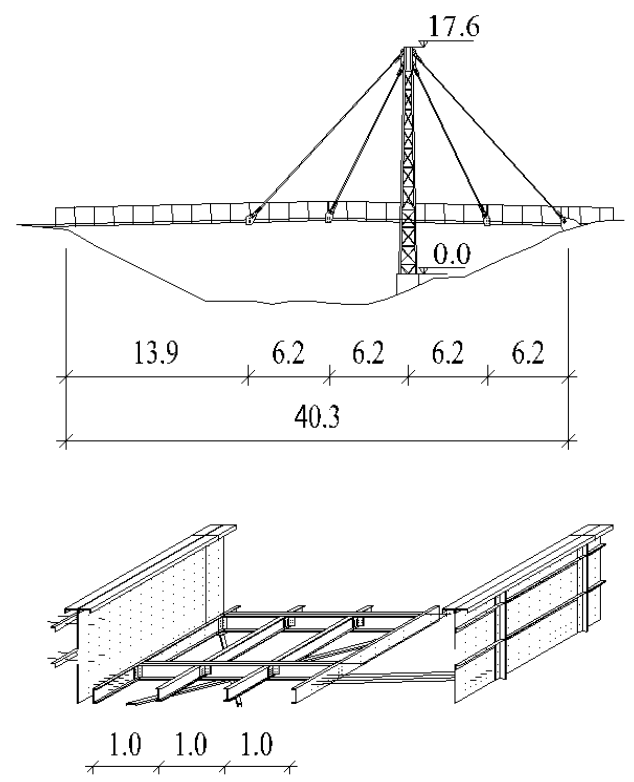

Fig. 5. Kolding, Denmark (1997).

Table 1. Aberfeldy bridge: main frequencies (Hz) - Damping (\%).

\begin{tabular}{lcccccccc}
\hline Mode & 1 & 2 & 3 & 4 & 5 & 6 & 7 & 8 \\
\hline V-1995 & 1.59 & 1.92 & 2.59 & 3.14 & 3.63 & 4.0 & 4.60 & 5.10 \\
& $(.84)$ & $(0.94)$ & $(1.20)$ & & & & & \\
V-2000 & 1.52 & 1.86 & 2.49 & 3.01 & 3.50 & 3.91 & 4.40 & 4.93 \\
& $(0.4)$ & $(.70)$ & $(0.70)$ & $(.80)$ & $(.60)$ & $(.90)$ & $(.80)$ & $(1.80)$ \\
V-2011 & 1.49 & 1.77 & 2.41 & - & - & - & - & 5.13 \\
\hline H-1995 & 1.00 & 2.81 & - & - & - & - & - & - \\
H-2000 & 0.98 & 2.73 & - & - & - & - & - & - \\
& $(1.00)$ & $(1.20)$ & & - & - & & & \\
H-2011 & 0.93 & 2.58 & - & - & - & - & - & - \\
\hline T-1995 & 3.44 & 4.31 & - & - & - & - & - & \\
T-2000 & 3.48 & 4.29 & - & - & - & - & - & - \\
& $(5.50)$ & $(3.20)$ & & - & - & & & \\
T-2011 & 3.39 & - & - & - & - & - & - & - \\
\hline
\end{tabular}

\section{Bridge Morphology}

The proposed pedestrian six span cable stayed bridge is conceived as an entirely FRPmade structure. First proposed [29] with a system of 100 ( $\phi 20)$ cables, the updated solution (Fig. 6) includes ( $\phi$ 12) pultruded PCFRP cables fastened by split wedge anchorages. The deck consists of (Fig. 7): 1) U-shaped elements either 360×108 or 
$300 \times 90 \mathrm{~mm}$, respectively adopted for a) the longitudinal beams (total weight $=130$ $\mathrm{kN}$ ), which cables are connected to and b) the bracing elements (total weight $=110$ $\mathrm{kN}$ ); 2) panel elements (total weight $=350 \mathrm{kN}$ ) adhesively joined to each other; 3 ) steel bolted GFRP flange. Antennas (Fig. 8) mainly consist of: 1) 4 vertical Double Web Beam (DWB) hybrid elements, whose flange is layered with carbon and glass reinforcement (total weight $=400 \mathrm{kN}$ ); 2) a bracing system of U-shaped elements $(300 \times 90 \mathrm{~mm})$, with a total weight of $230 \mathrm{kN} ; 3)$ bolted connections assembled through a system of FRP elements (total weight $=200 \mathrm{kN}$ ) cut out from DWB profiles. The mechanical properties of the adopted material are reported in Tab. 2.

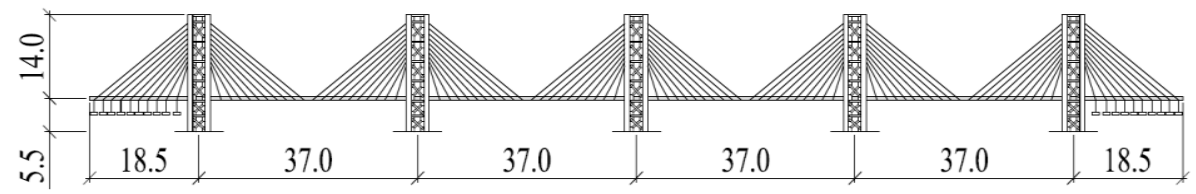

2.5

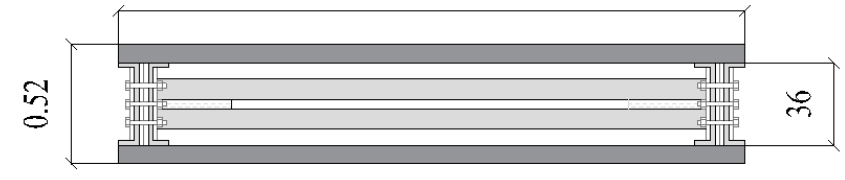

Fig. 6. Proposed entirely FRP-made system: longitudinal view (top) and deck sections (bottom) (dimensions in meters).

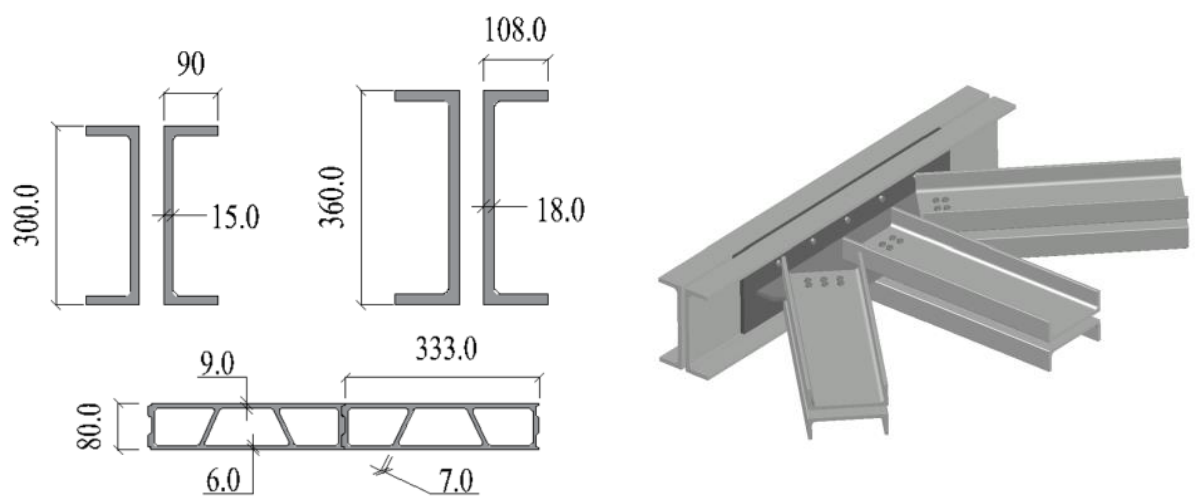

Fig. 7. Deck system (Total weight $\approx 600 \mathrm{kN}-1.3 \mathrm{kN} / \mathrm{m}^{2}$ ). Left: Deck Longitudinal Beams (top); Box Profiles (bottom). Right: deck diagonal and transversal elements (dimensions in millimeters). 


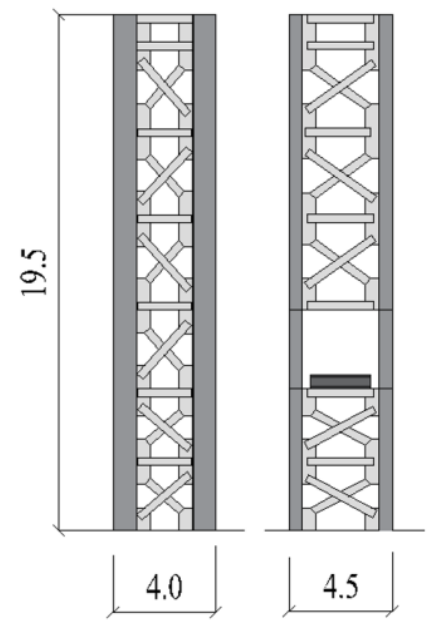

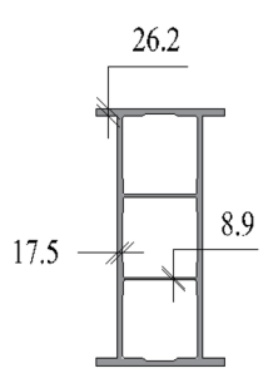

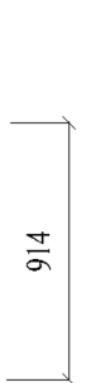

457
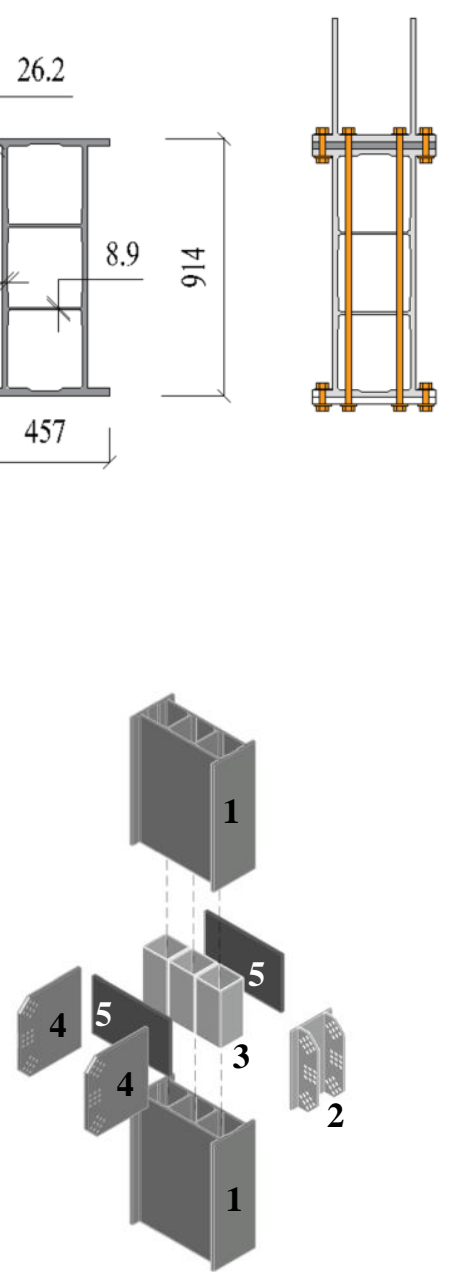

Fig. 8. Antennas (Total weight $\approx 850.0 \mathrm{kN}-1.8 \mathrm{kN} / \mathrm{m}^{2}$ ). Top: main dimension in meters (left); DWB section (mm) and bolt system to connect flange and DWB (right). Bottom: column subelements. DWB (1); Flanges (2, 4); internal tubular stiffener (3); contrasting plates (5).

Table 2. Material mechanical properties: $\mathrm{E}=$ Young modulus (GPa); $\mathrm{G}=$ shear modulus (GPa) $\mathrm{f}=$ axial strength $(\mathrm{MPa}) ; \tau=$ shear strength $(\mathrm{MPa})$; Tension $(+)$; Compression (-).

\begin{tabular}{lllllll}
\hline Mode & $\mathrm{E}_{0}$ & $\mathrm{E}_{90}$ & $\mathrm{G}$ & $\mathrm{f}_{0}$ & $\mathrm{f}_{90}$ & $\tau$ \\
\hline U-shaped & 24.0 & 10.0 & 3.0 & $+240,-240$ & 45 & 20.0 \\
DWB & 39.0 & 10.0 & 3.0 & $+206,-206$ & 45 & 20.0 \\
Panel & 27.00 & 14.00 & 3.0 & $+350,-205$ & 100 & 20.0 \\
CFRP cables & 164.0 & N.A. & N.A & 2275 & N.A. & N.A. \\
\hline
\end{tabular}




\section{$4 \quad$ Required Performances}

The bridge has been conceived in order to respect Serviceability (SLS) and Ultimate Limit (ULS) States. Referring actions include seismic, pedestrian, wind and fire loads, opportunely combined. Principal performance requirements regard 1) comfort, as far as pedestrian load is considered; 2) dynamic effects consequent to the wind action; 3 ) local and global instability; 4) connections; 5) maintenance and life cycle assessment. Some of previous requirements have been partially met, while others (wind actions, fire and impact loads, structural robustness, maintenance life cycle) are being studied with particular attention to the wind load effect. A discussion will follow, being aware of the non-exhaustive review.

\subsection{Pedestrian Induced Actions}

The pedestrian load should be assumed equal to $5.0 \mathrm{kN} / \mathrm{m}^{2}$ (SLS), including the dynamic effect. The pedestrian comfort should be controlled through dynamic analysis. Derogation of dynamic analyses depends on bridge frequencies and are differently ruled in international codes and recommendations. According to Euro Code [30], for any part of the deck, the acceleration limits are $\left.\left(\mathrm{m} / \mathrm{s}^{2}\right): 1\right) 0.7$ for vertical vibrations; 2 ) 0.2 and 0.4 for horizontal vibrations respectively due to normal use and exceptional crowd condition. Those limits can be considered satisfied if the fundamental frequencies $(\mathrm{Hz})$ are greater or equal to 5.0 (vertical) and 2.5 (horizontal and torsional). Sétra [22] suggests four different Risk Levels and, for each level, (Tab. 3) defines a vertical acceleration range to be satisfied; further on, it provides a lower limit equal to 0.1 $\mathrm{m} / \mathrm{s}^{2}$ for the horizontal acceleration, in order to avoid lock in phenomena.

According to BSI [31], the maximum vertical acceleration can be evaluated representing pedestrians through pulsating forces, that simulate the steps of walking (or jogging) pedestrians in normal or crowd conditions. Forces depend on the 1) reference amplitude $\left.\left(\mathrm{F}_{0}\right) ; 2\right)$ a factor $(\gamma)$ that allows to reduce the induced forces, including unsynchronized combinations; 3 ) the number $(\mathrm{N})$ of pedestrians in the group; 4) a factor (k), whose value is function (Fig. 9) of the pulsating force frequency: different frequencies $\left(f_{v}\right)$ need to be considered, including the fundamental structural ones. The peak vertical acceleration consequent to those forces should be less than $0.8 \mathrm{~m} / \mathrm{s}^{2}$ if the bridge is classified as primary route for school in major urban centres.

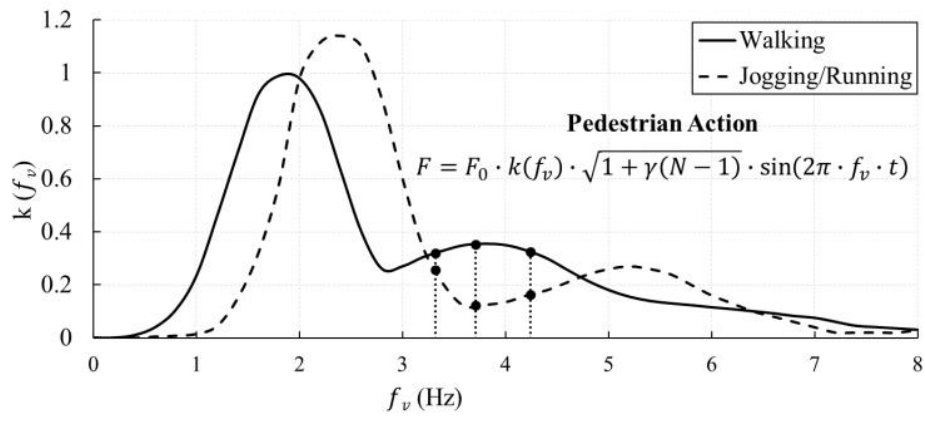

Fig. 9. Pedestrian load: Combined factor (k) vs. structural vertical frequency [31]. 
Table 3. Acceleration $\left(\mathrm{m} / \mathrm{s}^{2}\right)$ range vs. risk level Sétra (2006) [22].

\begin{tabular}{lllll}
\hline Vertical & $<0.5$ & $0.5-1.0$ & $1.0-2.5$ & $>2.5$ \\
\hline Comfort Level & Maximum & Mean & Minimum & Uncomfortable \\
\hline Horizontal & $<0.15$ & $0.15-0.30$ & $0.3-0.8$ & $>0.8$ \\
\hline
\end{tabular}

\subsection{Wind Induced Actions}

A referring velocity $\left(\mathrm{v}_{\mathrm{r}}\right)$ of $27 \mathrm{~m} / \mathrm{s}$ has to be assumed if a 50-years return period is considered [32]. The required construction performance at service and ultimate limit state can be verified through static force methodology, if mandatory requirements are satisfied to exclude some negative phenomena due to vortex, galloping, torsional divergence and flutter. Those requirements need to be checked considering a referring wind velocity of $\approx 30 \mathrm{~m} / \mathrm{s}$ (500-years return period). A simplified preliminary check can be performed adopting the recommendation proposed for standard bridge typology [33], but specific studies are required.

\subsection{Seismic Load}

Having fixed that the footbridge interruption cannot cause emerging situation, the referring period adopted for the evaluation of the seismic action is equal to 50 years [32]. Life Safe $\left(\mathrm{T}_{\mathrm{r}}=475\right.$ years; $\left.\mathrm{PGA}_{475} \approx 0.12 \mathrm{~g}\right)$ and Damage $\left(\mathrm{T}_{\mathrm{r}}=50\right.$ years; $\mathrm{PGA} \mathrm{A}_{50}=$ $0.055 \mathrm{~g}$ ) limit states need to be considered, adopting elastic spectra along the Horizontal and Vertical directions. Considering a frequency $(\mathrm{Hz})$ range in between 2.0 and 5.0 , the maximum spectra accelerations, assuming $\xi=2.0 \%$, are: 1 ) $\approx 0.40 \mathrm{~g}$ (Life Safe) and $0.17 \mathrm{~g}$ (Damage), along horizontal direction; 2$) \approx 0.09 \mathrm{~g}$ (Life Safe) and $0.03 \mathrm{~g}$ (Damage), along vertical direction.

\subsection{Element Global and Local Instability}

The design values of actions that trigger element instability can be determined through experimental tests. Alternatively, or in combination with, they can be evaluated based on numerical and analytical methods, including the effect of imperfections. The Italian recommendation [8] defines the methodology to be adopted for evaluating those values as function of local instability.

\subsection{Joints and Cable Anchorages}

The Italian recommendation [8] allows bolted, riveted or bonded joints. Regarding bolted joints, without excluding FRP ones, stainless steel bolts need to be adopted in combination with rigid washers under nut and bolt head: 1) geometric limitations and shear forces distribution are given for each row of bolts; 2) the considered failure mechanisms regard net-section, bolt shear, bearing, shear-out, pull-out. Washers and fastenings need to be properly pre-stressed to guarantee a pseudo-ductile behavior. Regarding to bonded joints, the interaction debonding/opening needs to be considered based on mixed mode of fracture (I/II). 
As far as cable systems are concerned, different anchorages have been proposed as discussed in [34-37]. Principal problems concern the reduction of the shear stress in between cable and anchorages. In Meier et al (1998) [38] is described the patent of a solution based on a casting Load Transfer Media (LTM), that is a gradient material whose modulus of elasticity continuously increases, exhibiting its greatest value at the free cable end. This solution has been adopted for the Stork Bridge (1996) in Winterthur (Switzerland). Further on, as split wedge anchorages are concerned, the shear stress reduction can be achieved either with differential angles [39] between wedges and barrel or adopting a curved shape [40] at the internal and external surfaces of the barrel and wedge respectively. So that, numerical and experimental studies are needed, as far as wedge anchorage are concerned.

\subsection{Durability and Maintenance}

The performances of an FRP structure need to be guaranteed over the referring time: the design, taking in account the environmental conditions, should include the maintenance program [8]. Additive and protective coverings can be used to mitigate the effect of exposure. Theoretical models, experimental tests and studies of similar existing structures can be considered for evaluating the influence of durability on structural performance. The importance of the coating technology was evident in the Aberfeldy footbridge [28]: 1) it was observed that after 20 years in service, polyester and polyethylene coats respectively protected GFRP principal structural elements and aramid cables; 2) differently, unprotected or wrongly protected part of handrail and cable (at the connections) caused material deterioration instead. A similar conclusion regarded Pontresina [16] exposed to an alpine climate with an annual temperature ranging between -20 and $25^{\circ} \mathrm{C}$; the inspection after eight years of service, albeit denoting the presence of cracks and a strength reduction comprised between $13 \div 18 \%$, showed that most of the durability deficiencies were mainly due to inappropriate constructive details. In conclusion, the PGFRP elements 1) can offer long term performance when adequately conceived and produced; 2) UV radiation effects could be circumscribed to aesthetical changes [41].

\section{$5 \quad$ Structural Modelling and Verifications}

The static and dynamic numerical studies have been carried out through a FEM model (Fig. 10) by means of the SAP 2000 software [42]: 1) the Box Profiles (Fig. 7) of the deck have been modelled through orthotropic linear shell elements; 2) cables and beams have been modelled through elastic one-dimensional frame elements.

One of the design goal was the limitation of deck acceleration, in order to increase the pedestrian comfort. This was achieved by increasing frequency values as much as possible, obtaining (Tab. 4): 1) horizontal frequencies greater than $2.5(\mathrm{~Hz})$ that [30] is the threshold to be overcome in order to satisfy the comfort requirements; 2) vertical frequencies in the post peak zone for both jogging and running condition (Fig. 9). Specifying that dynamic effects due to wind action are under study, it can be concluded that Capacity/Demand safety factor resulted greater than one, as far as damage and 
ultimate limit states are concerned. Some results concerning pedestrian comfort, joints and cable system will be briefly discussed in the following.
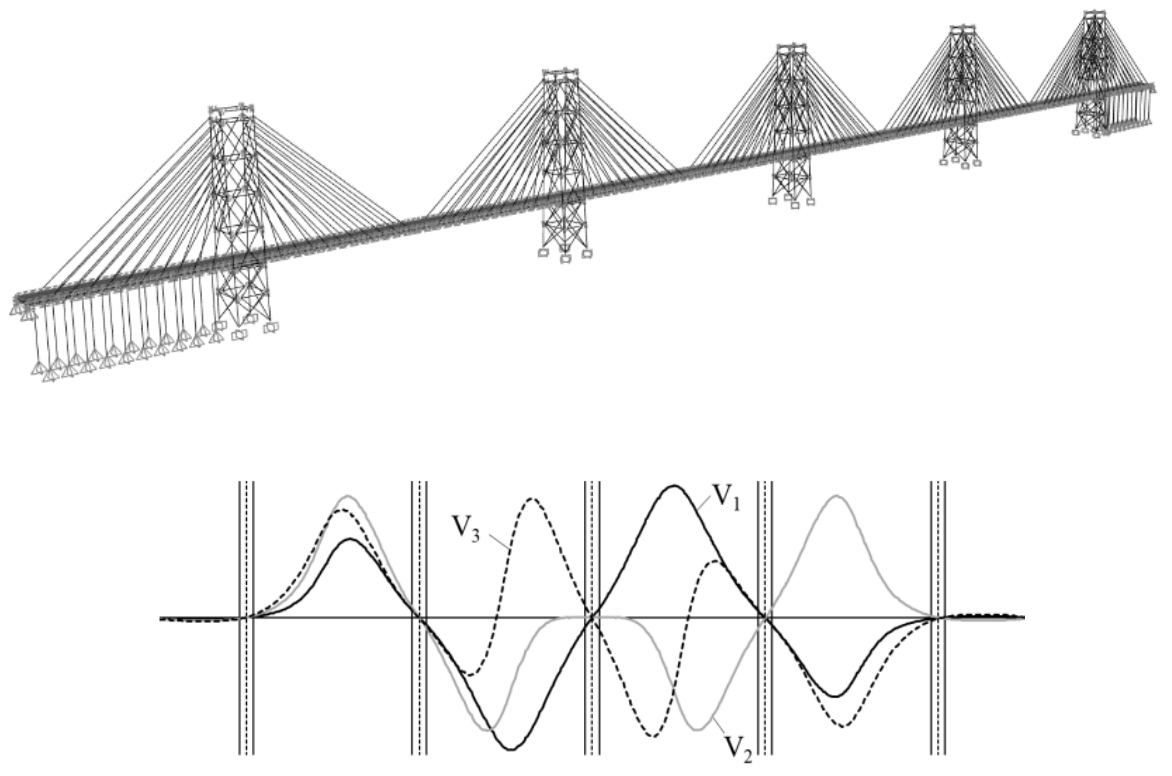

Fig. 10. FEM Model: 3D view (top) and main vertical modes and frequencies (bottom).

Table 4. Main Frequencies: Horizontal (H); Vertical (V); Torsional (T).

\begin{tabular}{|c|c|c|c|c|c|c|c|c|}
\hline $\mathrm{H}_{1}$ & $\mathrm{H}_{2}$ & $\mathrm{H}_{3}$ & $\mathrm{~V}_{1}$ & $\mathrm{~V}_{2}$ & $\mathrm{~V}_{3}$ & $\mathrm{~T}_{1}$ & $\mathrm{~T}_{2}$ & $\mathrm{~T}_{3}$ \\
\hline 2.98 & 3.14 & 3.35 & 3.32 & 3.71 & 4.24 & 7.29 & 7.41 & 7.54 \\
\hline
\end{tabular}

\subsection{Pedestrian Comfort}

Dynamic simulations have been carried out in agreement with [31] simulating crowd and pedestrian group condition. A critical damping of $0.8 \%$ has been adopted, considering it a lower bound based on the previously introduced literature values. The results of the dynamic analyses highlighted a peak acceleration lower than $0.7 \mathrm{~m} / \mathrm{s}^{2}: 1$ ) it is lower than the limit $\left(0.8 \mathrm{~m} / \mathrm{s}^{2}\right)$ suggested in [31]; 2) the comfort level can be classified as "mean" (Tab. 3) according to [22]. It is worth noticing that 1) adjustments are under development, in order to reduce the deck accelerations, hopefully achieving a maximum comfort level; 2) those adjustments will be decided based on the results of the wind effect studies.

\subsection{Joints}

The bolt connections have been satisfactorily verified through the methodology proposed in $[7,8]$. Further on, numerical controls have been carried out through nonlinear 
FEM models: 1) the software ABAQUS [43] has been used; 2) a friction contact has been adopted for bolt/beam interaction; 3) an equivalent system of loads has been applied to reproduce the maximum forces observed in the global model; 4) stress levels have been compared with the experimental strength values (Fig. 11) reported in [44], together with the experimental crack pattern obtained. Studies under development regard the adoption of slip-critical connection [45]. Among studies can be mentioned those concerning prediction of crack pattern for small specimens [46] and webflange junctions [47].
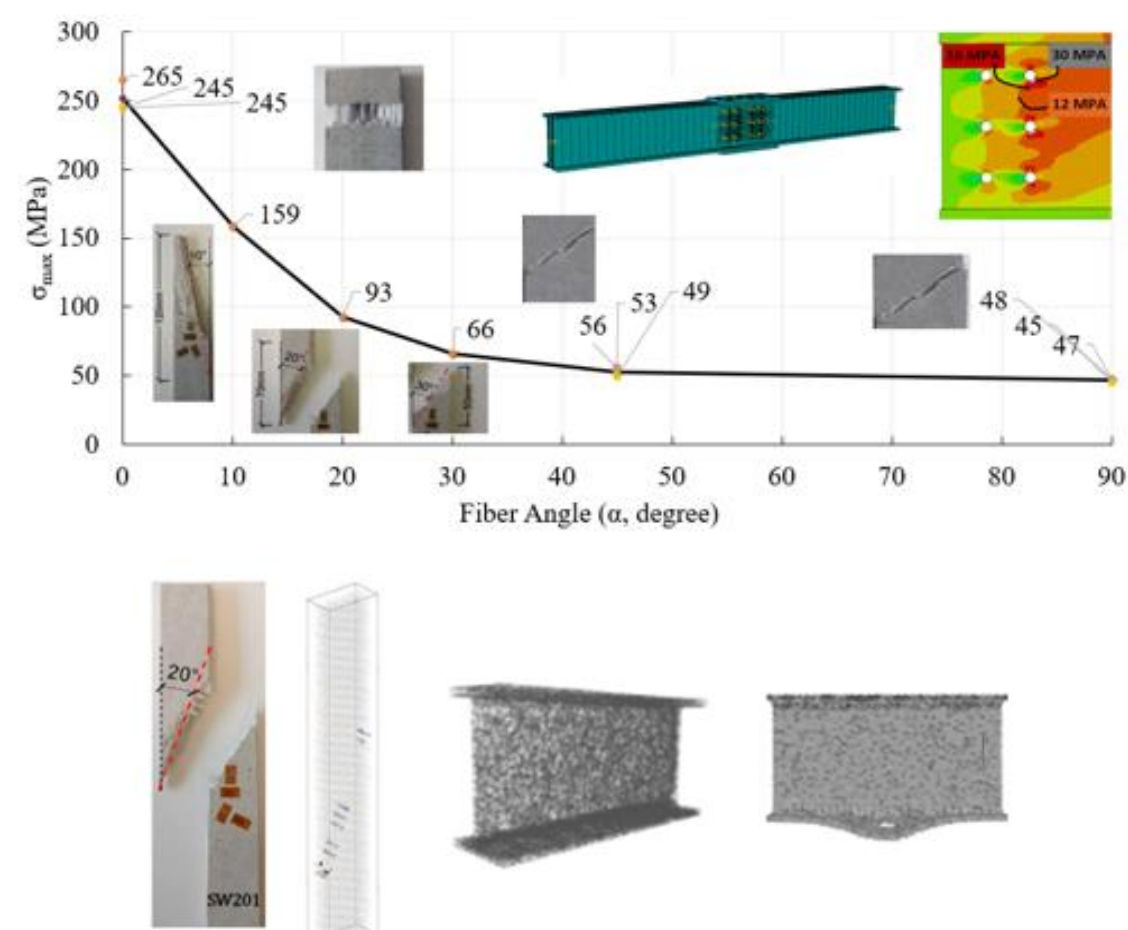

Fig. 11. Joint verifications: material strength vs fiber-load angle (top) and lattice model results (bottom).

\subsection{Cable System}

The Split Wedge Anchorage System (Fig. 12) consists of an external steel barrel, and three steel wedges, having the same height of the barrel.

The PCFRP cable ( $\phi 12)$ has: 1$)$ the external surface post-treated, through a pullwinding process, to increase the bond strength; 2) free ends, comprised within wedges, protected by an aluminum sleeve ( $1 \mathrm{~mm}$ thick) glued with epoxy resin. 
Main mechanical properties have been reported in Table 2: the breaking load $(257 \mathrm{kN}$ in average) is five times greater than the maximum axial load evaluated at ultimate limit state.
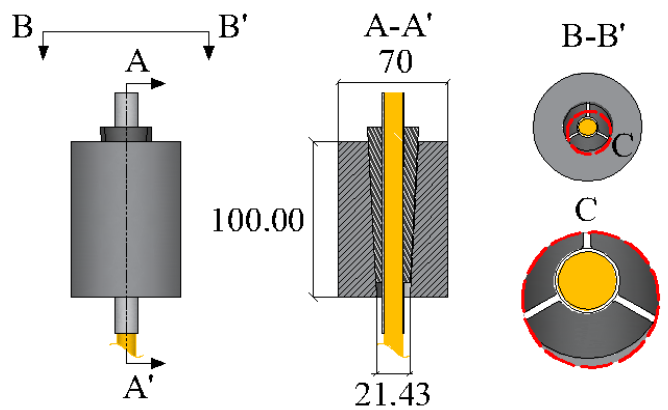

Fig. 12. Proposed Anchorage system: geometry (dimensions in millimeters).

Wedges play a crucial role in the anchorage system: their geometry has to be designed in order to avoid that normal and tangential peak stresses are located in the same point of the cable, triggering its premature failure. Based on the aforementioned literature works [39,40], a Double Angle (DA) solution (Fig. 13, Left) has been developed for the external surfaces of wedges, having a double slope along the height: 1) part of them $(25 \mathrm{~mm})$ have the same tilting angle $\left(3^{\circ}\right)$ of the barrel inner surface and 2) the remaining $75 \mathrm{~mm}$ are tilted $\left(3.1^{\circ}\right)$ forming a differential angle of $0.1^{\circ}$ with the inner surface of the barrel. In order to compare the proposed solution with a traditional one, a further wedge system has been designed with a constant 3 degree tilting angle (Fig 13, Right).

The design of the adopted solutions has been assisted by FEM nonlinear analyses [29].

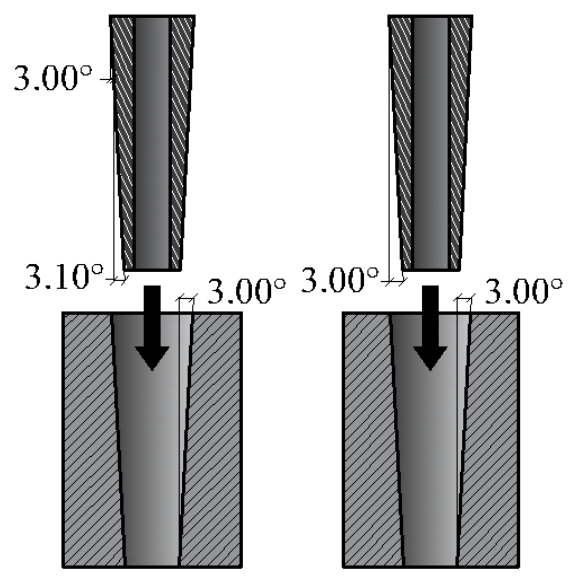

Fig. 13. Proposed Double Angle wedges (left) and traditional Single Angle solution (Right). 
Both solutions have been produced and tested [29,37] at the Laboratory of the Department of Structural and Geotechnical Engineering (Sapienza University of Roma): 1) tests have been performed imposing a displacement-controlled loading; 2) a specific setup (Fig. 14) has been conceived: it was composed of two $40 \mathrm{~mm}$ thick perforated steel plates connected to the machine by means of high-strength bolts $(\phi 16 \mathrm{~mm})$. PCFRP cables, having a length of $600 \mathrm{~mm}$, have been passed throughout the central hole of the plates and then fastened by two split wedge anchorages at the cable free ends.

Results of tensile tests have been provided in terms of force-displacement curves (Fig. 14): the displacements have been evaluated by means of a DIC (Digital Image Correlation) software [37] developed for this purpose. It can be noted that the SA system returned values of ultimate loads between $183 \mathrm{kN}$, the minimum load registered among the whole set of specimens, and $232 \mathrm{kN}$. DA prototypes exhibited values of ultimate load equal to $222 \mathrm{kN}$ and $257 \mathrm{kN}$, respectively. This last value is close to the mean strength of the cable $(257 \mathrm{kN})$ and confirms that the proposed system satisfactorily employs the PCFRP cable capacity.
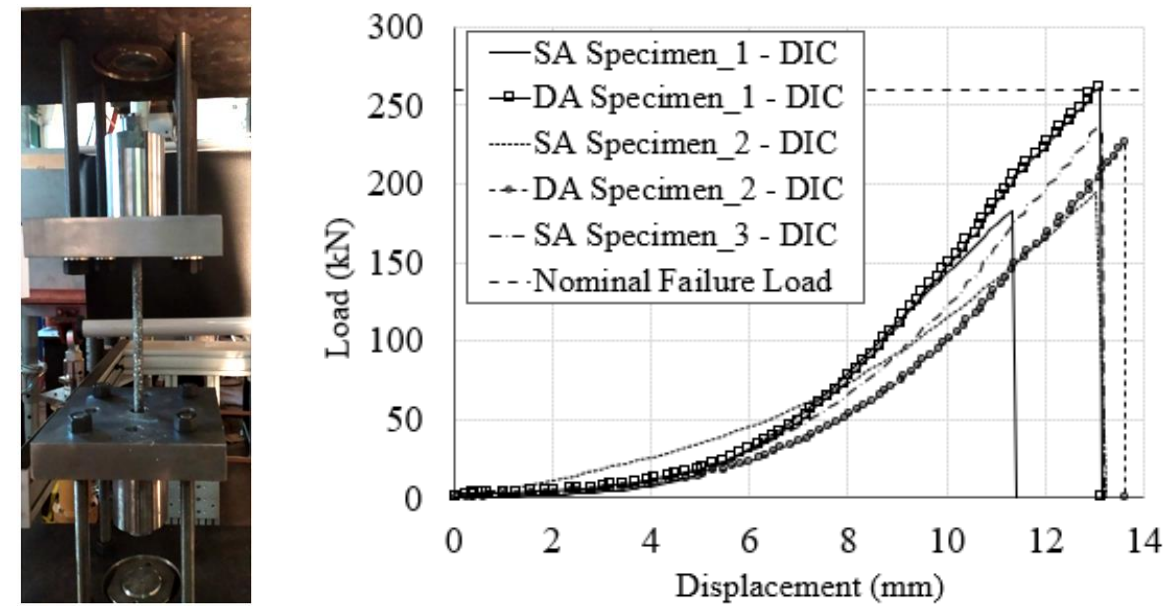

Fig. 14. Anchorage system. Testing setup (left) and experimental test results in terms of forcedisplacement curves (right).

\section{References}

1. Bakis, C.E., Bank L.C., Brown V., Cosenza E., Davalos J.F., Lesko J.J., Machida A., Rizkalla S.H., Triantafillou T.C.: Fiber-reinforced polymer composites for construction State-of-the-art review. Journal of composites for construction 6(2): 73-87 (2002).

2. Bank, L.C.: Application of FRP Composites to Bridges in the USA. Proc. of the international Colloquium on Application of FRP to Bridges. Japan Society of Civil Engineers (JSCE), Tokyo, Japan January 20 (2006). 
3. Hollaway, L.C.: A review of the present and the future utilization of FRP composites in the civil infrastructure with reference to their important in-service properties. Construction and building materials 24: 2419-2445 (2010).

4. Mara, V., Haghani, R., Harryson, P.: Bridge decks of fibre reinforced polymer (FRP): A sustainable solution. Construction and building materials 50: 190 - 199 (2014).

5. Clark, J.L.: Structural design of polymer composites. The European Structural Polymeric Composites Group, Edited by J.L. Clarke - E \& FN Spon, London, UK. ISBN 0-20347513-5 (1996).

6. Bank, L.C.: Composites for construction: structural design with FRP materials. John Wiley \& Sons. ISBN-13: 978-0471-68126-7 (2006).

7. CEN 250: Fiber Reinforced Polymer. Scientific and Technical Report/ TC250, WG4 (2014).

8. CNR: Guide for the Design and Construction of Structures Made of FRP Pultruded Elements. DT 205/2007, Italian National Research Council. Rome, Italy (2007).

9. Wei, X., Russel, J., Živanović, S., Mottram, J.T.: Measured dynamic properties for FRP footbridges and their critical comparison against structures made of conventional construction materials. Composite Structures 223: 110956 (2019).

10. Monsanto Plastics: House of the future. The Architect and Building News, 212(15): $478-$ 485 (1957).

11. McCormick, F.C.: Why not plastic bridges? J. Struct. Div. ASCE98(ST8): 1757 - 1767 (1972).

12. Alper, H., Barton, F.W., McCormick, F.C.: Optimum design of a reinforced plastic bridge girder. Computers \& Structures 7: 249-236 (1977).

13. Areiza-Hurtado, M., Bansal, A., Paulotto, C., Primi, S.: FRP girder bridges: lessons learned in Spain in the last decade. Proc. of 6th Int. CICE Conf. on FRP Composites in Civil Eng., Rome, Italy (2012).

14. Górriz, P., Bansal, A., Paulotto, C., Primi, S., Calvo, I.: Case Study of Innovative Projects - Successful Real Cases. Composite Solutions for Construction Sector, Chapter 3, Intech Open (2017).

15. Siwowski, T., Kaleta, D., Rajchel, M.: Structural behaviour of an all-composite road bridge. Composite Structures 192: 555-567 (2018).

16. Keller, T., Bai, Y., Vallée, T.: Long-Term Performance of a Glass Fiber-Reinforced Polymer Truss Bridge. Journal of Composites for Construction 11(1): 99 - 108 (2007).

17. Bai, Y., Keller, T., Vallée, T.: Dynamic behaviour of an all-FRP pedestrian bridge. Proc. of APFIS Conference on FRP in Structures, Hong Kong (China) (2007).

18. Adilardi, A., Frasconi, L.: Design of a pedestrian bridge made with pultruded profiles of fibreglass-reinforced plastics in Prato. Proc. of 3rd Int. Conference on Footbridges, Porto Portugal (2008).

19. Wei, X., Boscato, G., Russell, J., Adilardi, A., Russo, S., Živanović, S.: Experimental Characterisation of Dynamic Properties of an All-FRP Truss Bridge. Dynamic of Civil Structures Conference Proc. of the Society for Experimental Mechanics Series 2: 37-35. Springer, Cham - ISBN 978-3-319-74420-9 (2019).

20. Sobrino, J.A., Pulido, M.D.G.: Towards Advanced Composite Material Footbridges. Structural Engineering International 12(2), $84-86$ (2002).

21. Drygala, I.J., Polak, M.A., Dulinska, J.M.: Vibration serviceability assessment of GFRP pedestrian bridges. Engineering Structures 184: 176-185 (2019).

22. Sétra: Assessment of vibrational behaviour of footbridges under pedestrian loading. Technical guide: Footbridges. Published by the Service d'Études techniques des routes et auto- 
routes, realized within a Sétra/Afgc (French association of civil engineering) working group (2006).

23. Wei, X., Russell, J., Živanović, S., Mottram, J.T.: Experimental Investigation of the Dynamic Characteristics of a Glass-FRP Suspension Footbridge. In: Caicedo J., Pakzad S. (eds) Dynamics of Civil Structures, Volume 2. Conference Proceedings of the Society for Experimental Mechanics Series. Springer, Cham. https://doi.org/10.1007/978-3-31954777-0_5 (2017).

24. Votsis, R.A., Stratford, T.J., Chryssanthopoulos, M.K., Tantele, E.A.: Dynamic assessment of a FRP suspension footbridge through field testing and finite element modelling. Steel and Composite Structures 23(2): 205-215 (2017).

25. Burgoyne, C.J., Head, P.R.: Aberfeldy Bridge - an advanced textile reinforced footbridge. TechTextil Symposium, Frankfurt, Germany (1993).

26. Górski, P., Stankiewicz, B., Tatara, M.: Modal parameter identification of all-GFRP composite cable-stayed footbridge in Denmark Case. Proc. of MATEC Web of Conferences 107. DYN-WIND'2107 (2017).

27. Cadei, J., Stratford, T.: The design, construction and in-service performance of the allcomposite Aberfeldy footbridge. Advanced Polymer Composites for Structural Applications in Construction, ICE Publishing: 445-453 (2002).

28. Stratford, T.: The Condition of the Aberfeldy Footbridge after 20 Years in Service. Presented at Structural Faults and Repair Conference, Edinburgh, UK (2012).

29. Quadrino, A.: FRP Structures. Design of Cable Stayed pedestrian bridge: development and implementation of an anchorage system. Ph.D. Program in Structural and Geotechnical Engineering -Sapienza University of Rome. Advisor: N. Nisticò (2020).

30. Euro code 0: Basis of structural design, Annex A2.4.3 Verification concerning vibration for footbridges due to pedestrian traffic. European Committee for Standardization, Brussels, Belgium (2006).

31. BSI: Actions on structures, Part 2: Traffic loads on bridges UK National Annex to Euro Code 1. British Standard Institution (2008).

32. MIT: Italian Technical Code for Constructions. Law Decree of the Minister of the Infrastructures and Transport (MIT) (in Italian) (2018).

33. CNR: Guide for the evaluations of Wind Actions and their Effects on Constructions (in Italian). DT 207/2008, Italian National Research Council. Rome, Italy (2008).

34. ACI: Prestressing Concrete structures with FRP Tendons. ACI 440.4R, American Concrete Institute, Farmington Hills, MI (2004).

35. Schmidt, J.W., Bennitz, A., Täljsten, B., Goltermann, P., Pedersen, H.: Mechanical anchorage of FRP tendons-a literature review. Construction and Building Materials 32, 110121 (2012).

36. Wang, L., Zhang, J., Xu J., Han, Q.: Anchorage systems of CFRP cables in cable structures - A review. Construction and Building Materials 160: 82-99 (2018).

37. Damiani, M.; Quadrino, A.; Nisticò, N.: FRP Cables to Prestress RC Beams: State of the Art vs. a Split Wedge Anchorage System. Buildings 11, 209 (2021).

38. Meier, U., Meier, H., Kim, P.: Anchorage device for high-performance fiber composite cables. US Patent 5713169 (1998).

39. Sayed-Ahemed, E.Y., Shrive, N.G.: New steel anchorage system for post tensioning applications using carbon fibre reinforced plastic tendons. Can. J. Civ. Eng.25(1): 113 - 127 (1998).

40. Al-Mayah, A., Soudki, K., Plumtree, A.: Development and assessment of a new CFRP rod-anchor system for prestressed concrete. Applied Composite Materials 13(5): 321-334 (2006). 
41. Correia, J.R., Cabral-Fonseca, S.F., Branco, F.A., Ferreira, J.G., Eusébio, M.I., Rodrigues, M.P.: Durability of Pultruded Glass-Fiber-Reinforced polyester profiles for structural applications. Mechanics of Composite Materials 42(4): 325 -338 (2006).

42. CSI: Manual. Comp. and Struc. Inc. Berkeley, Cal. USA (2009).

43. Simulia: ABAQUS Users' Manual v. 6.13., Simulia Corp (2013).

44. Quadrino, A., Penna, R., Feo, L., Nisticò, N.: Mechanical characterization of pultruded elements: Fiber orientation influence vs web-flange junction local problem. Experimental and numerical tests. Composites Part B: Engineering, 142. 68-84 (2018).

45. Feo, L., Latour, M., Penna, R., Rizzano, G.: Pilot study on the experimental behavior of GFRP-steel slip-critical connections. Composites Part B 115: 209-222 (2017).

46. Gaetani, A., Fascetti, A., Nisticò, N.: Parametric investigation on the tensile response of GFRP elements through a discrete lattice modeling approach. Composites Part B: Engineering (2019).

47. Fascetti, A., Feo, L., Nisticò, N., Penna, R.: Web-flange behavior of pultruded GFRP Ibeams: A lattice model for the interpretation of experimental results. Composites Part B: Engineering, 100, 257-269 (2016). 